\title{
Effective and safe translation of intensified insulin therapy to general internal medicine departments
}

\author{
V.Jörgens, M. Grïßer, U. Bott, I. Mühlhauser and M. Berger \\ Abteilung für Stoffwechsel und Ernährung (WHO-Collaborating Centre for Diabetes), Medizinische Klinik \\ der Heinrich-Heine-Universität Düsseldorf, Düsseldorf, FRG
}

\begin{abstract}
Summary. Up to now all published experience with intensified insulin therapy has originated from specialized diabetes centres. However, even in diabetes centres and under research conditions intensification of insulin therapy may substantially increase the risk of severe hypoglycaemia. The aim of the present study was to demonstrate the feasibility of effectively and safely transfering intensified insulin therapy based upon a 5-day in-patient treatment and teaching programme from a University diabetes centre to non-specialized general hospitals. A total of nine general hospitals were recruited; the University diabetes centre served as a reference centre. From each general hospital a nurse and a dietitian were trained as diabetes educators, and a diabetes unit with about 10 beds was organized within each department of internal medicine. A total of 697 consecutively admitted Type 1 (insulin-dependent) diabetic patients (age $26 \pm 7$ years, duration of diabetes $8 \pm 7$ years) who participated in the programme either in one of the general hospitals $(n=579)$ or in the reference centre $(n=118)$ were re-examined after 1,2 and 3 years. Insulin therapy was intensified to a similar extent in the reference centre and the general hospitals: at the 3-year follow-up about $80 \%$ of the patients injected insulin at least
\end{abstract}

three times daily or used continuous subcutaneous insulin infusion $(10 \%)$, and about $70 \%$ reported measuring blood glucose levels more than twice per day. $\mathrm{HbA}_{1}$ levels were lowered $(p<0.0001)$ to comparable levels, i. e. from $10.6 \%$ (reference centre) and $9.9 \%$ (general hospital), respectively, at baseline to $9.4 \%$ and $9.3 \%$, respectively, at the 3 -year follow-up. The yearly incidence rates of severe hypoglycaemia decreased from 0.23 (reference centre) and 0.29 (general hospitals), respectively, during the year before intensification of insulin therapy, to 0.19 (NS) and $0.12(p<0.005)$, respectively, during the third year of follow-up. Days spent in hospital were reduced in both groups (from 11 and 7 days per patient per year, respectively, to 5 and 4 days, respectively, $p<0.0001$ ). In conclusion, this study shows that intensified insulin therapy based upon a structured and comprehensive training of the patients by diabetes educators can be effectively and safely translated from a specialized University diabetes centre to general medicine departments.

Key words: Insulin therapy, education, hypoglycaemia, ketoacidosis, hospitalisation.
Technological developments have promoted major changes in clinical diabetology. Improvements in insulin preparations and insulin injection aids have rendered insulin therapy more comfortable for diabetic patients. In addition, the introduction of methods for measuring glycated haemoglobin $\left(\mathrm{HbA}_{1}\right)$ values and home blood glucose-monitoring have made continuous (near-)normalization of blood glucose concentrations feasible. Increasing experience in the use of blood glucose selfmonitoring and patient participation in treatment decision making, i.e. by self-adaptation of insulin dosages, have provided evidence that liberalization of hitherto strict dietary prescriptions is possible. Diabetic patients who practise intensified insulin therapy with daily blood glucose monitoring and immediate adjustment of insulin dosages can largely vary the timing and the amounts of carbohydrate intake, can skip meals altogether and can consume a prudent quantity of sucrose and sucrose-containing nutrients without losing good metabolic control [1, 2]. The possibility to abandon strict dietary regimens and at the same time to improve overall glycaemic control has motivated an increasing number of Type 1 (insulin-dependent) diabetic patients to opt for intensified insulin therapy.

So far, all published experience with intensified insulin therapy originates from specialized diabetes centres, but, usually only a minor part of the total population of Type 1 diabetic patients are treated in specialized diabetes centres. For instance, in Germany, for in-patient treatment the majority of patients are referred to regional non-spe- 
cialized hospitals, while out-patient care is almost exclusively provided by family physicians. If the achievements of modern clinical diabetology are to become amenable to all Type 1 diabetic patients, intensified insulin therapy has to be decentralized and to be offered at many more places. However, it has been doubted whether intensified insulin therapy can be performed safely by the majority of Type 1 diabetic patients outside specialized diabetes centres [3]. In fact, even in diabetes centres and under clinical research conditions intensified insulin therapy may be associated with a two- to three-fold increase in the frequency of severe hypoglycaemia $[3,4]$. Thus, real concern exists that in the hands of non-specialized health care providers efforts to lower glycosylated haemoglobin values will result in an excessive risk of severe hypoglycaemia.

We have previously shown that intensified insulin therapy can be practised effectively without increasing the risk of severe hypoglycaemia if it is based upon a structured 5 -day in-patient treatment and teaching programme $[1,2$, 5-10]. In this study, we document the feasibility of transferring this intensified insulin treatment and teaching programme for patients with Type 1 diabetes as performed at the diabetes centre of the University hospital of Düsseldorf to non-specialized general hospitals.

\section{Subjects and methods}

\section{Selection criteria for hospitals and patients}

Hospitals were considered eligible for participation in the study, if the following criteria were fulfilled: a) general country- or city-hospital with a minimum size of at least 80 beds for internal medicine; located within the Federal States of Nordrhein-Westfalen or BadenWürttemberg; b) the possibility to organize an in-patient diabetes unit of about 10 beds within the department of internal medicine; $c$ ) willingness to make available a medical team consisting of a physician, a nurse, and a dietitian to care for the diabetic patients.

Patients were considered eligible for recruitment if they fulfilled the following criteria: a) Type 1 diabetes was present; b) age 15 to 40 years; $c$ ) absence of advanced diabetic late complications (serum creatinine more than $177 \mu \mathrm{mol} / \mathrm{l}$; blindness); d) referral by family physician for in-patient diabetes treatment, e) were resident within $100 \mathrm{~km}$ from the diabetes centre. A history of (repeated) severe hypoglycaemia was not an exclusion criteria, whereas patients treated with continuous subcutaneous insulin-infusion (CSII) were not considered eligible.

\section{Study protocol}

A total of nine general hospitals were recruited for participation in the study. The Düsseldorf University hospital served as a reference centre. Each hospital was estimated to recruit about 80 patients. However, the recruitment period was limited to one year or until a maximum of 130 patients were recruited. All consecutively referred and eligible patients were to be included. Patients were investigated according to a standardized protocol before participation in the treatment and teaching programme (TTP) and 1,2, and 3 years thereafter. On admission, patients were informed about the nature of the study and asked for informed consent. Baseline data were collected by the responsible local physician, whereas all follow-up investigations were performed by two physicians (V.J. and M. G.) from the Düsseldorf centre.
All participating physicians, nurses and dietitians were trained in order to implement the 5-day TTP. For nurses and dietitians the training includes participation in a formal postgraduate training course for diabetes educators. The course was established by the German Diabetes Association in 1983 and consists of two blocks of 4 weeks each of theoretical and practical training concerning medical, psychosocial and educational aspects of diabetes care with a 6-month period in between, during which the participants should establish a structured TTP in their own hospitals [11]. For physicians the preparatory training includes participation in the Düsseldorf TTP as a guest observer. All physicians were trained in the interview techniques necessary to collect the baseline patient data. In order to ensure that the study protocol was achieved, e.g. inclusion of all consecutively admitted patients, accurate data collection and accurate measurements of principal study outcomes, e. g. $\mathrm{HbA}_{1}$ levels, performance was continuously monitored via peer review by the principal investigators from the co-ordinating centre in Düsseldorf.

\section{The diabetes treatment and teaching programme}

The programme has been described previously $[5,6,8]$. In short, patient education is considered an integral part of any treatment of persons with Type 1 diabetes. The teaching is delivered by a nurse and a dietitian in a structured Monday to Friday in-patient course for groups of up to 10 patients. The goal of the TTP is to motivate and enable the patients to strive for (near-)normoglycaemia, i.e. preprandial glycaemia around $5.5 \mathrm{mmol} / \mathrm{l}$ and to avoid hypoglycaemia. An additional major aim of the programme is to enable the patients to liberalize their diet. This includes variation of the amount and timing of carbohydrate intake, skipping meals altogether and a prudent consumption of sucrose-containing nutrients. Important general prerequisites for achieving these teaching and treatment goals are: preprandial and bedtime blood glucose self-monitoring three-four times per day; insulin therapy with two daily injections of intermediate acting (NPH-)insulin preparations in the morning and in the evening (before dinner or at bedtime), and injection of regular insulin before main meals; adaptation of the insulin dosages by the patients themselves without contacting a physician; recording results of metabolic self-monitoring, insulin dosages, hypoglycaemic episodes or other events relevant to glycaemic regulation in a diabetes logbook is recommended. The more liberal the diet becomes, the more frequent measurements of blood glucose and the more frequent injections of regular insulin and immediate adaptations of insulin dosages will be necessary to keep glycaemia in optimal control. After discharge, patients are followed-up by their family physicians, although consultation of a specialized diabetes outpatient clinic is possible on referral.

\section{Procedures}

The standardized interview addressed various aspects of diabetes care as previously described [8]. Severe hypoglycaemia was defined as a hypoglycaemic episode requiring assistance from another person and treatment by intravenous glucose or glucagon injection. Ketoacidosis was defined as a hyperglycaemic ketotic metabolic decompensation associated with clinical signs of ketoacidosis, and treatment provided in the hospital. Hospitalisations, diabetes-related or not, were assessed retrospectively for the last 3 years before the study, and for the respective preceding year at each 1-year follow-up examination. The validity of the method used has been shown previously [9].

Using an illustrated questionnaire with 39 items $[5,8]$ diabetesrelated knowledge was assessed at baseline, immediately after the TTP, and at the 1-year follow-up examination. In addition, patients were asked to present their diabetes log-books; frequencies of metabolic self-monitoring were assessed by analysing the log-book entries concerning the last 4 weeks before the follow-up examination 
Table 1. Numbers of patients recruited in each participating centre, and of those available and examined, respectively, at the follow-up examinations

\begin{tabular}{|c|c|c|c|c|c|c|c|}
\hline & \multicolumn{7}{|c|}{ No. of patients } \\
\hline & \multirow{2}{*}{$\begin{array}{l}\text { At entry } \\
\text { Recruited }\end{array}$} & \multicolumn{2}{|c|}{ At the 1-year follow-up } & \multicolumn{2}{|c|}{ At the 2-year follow-up } & \multicolumn{2}{|c|}{ At the 3-year follow-up } \\
\hline & & Available & Examined & Available & Examined & Available & Examined \\
\hline \multicolumn{8}{|l|}{ General hospitals } \\
\hline 1 & 119 & 115 & 113 & 113 & 109 & 110 & 104 \\
\hline 4 & 77 & 76 & 72 & 75 & 70 & 74 & 69 \\
\hline 5 & 56 & 55 & 53 & 54 & 52 & 53 & 50 \\
\hline 6 & 55 & 53 & 51 & 51 & 47 & 50 & 46 \\
\hline 7 & 87 & 83 & 83 & 80 & 78 & 77 & 74 \\
\hline 8 & 22 & 21 & 20 & 21 & 19 & 21 & 18 \\
\hline 9 & 50 & 48 & 48 & 48 & 47 & 47 & 46 \\
\hline
\end{tabular}

and by interview. Performance of glucagon administration by relatives or significant others in case of severe hypoglycaemia was evaluated by patient interview.

At baseline, the usual clinical and diabetes-related examinations and laboratory measurements were performed in each hospital using standard methods. Retinal status was assessed by the consultant ophthalmologist of the respective hospital. $\mathrm{HbA}_{1}$ was measured using a microcolumn method (Boehringer Mannheim, Mannheim, FRG), with a normal range of $5.6-7.4 \%$ (mean $\pm 2 \mathrm{SD}$ ). During the

Table 2. Baseline characteristics of patients

\begin{tabular}{|c|c|c|}
\hline & $\begin{array}{l}\text { Reference } \\
\text { centre } \\
(n=131)\end{array}$ & $\begin{array}{l}\text { General } \\
\text { hospitals } \\
(n=653)\end{array}$ \\
\hline Female (\%) & 50 & 48 \\
\hline Age (years) & $26 \pm 7$ & $26 \pm 7$ \\
\hline Duration of diabetes (years) & $8 \pm 8$ & $8 \pm 7$ \\
\hline Newly-diagnosed diabetes (\% patients) & 13 & $6^{\mathrm{a}}$ \\
\hline $\begin{array}{l}\text { Educational level (\% patients) } \\
\text { low/intermediate/high }\end{array}$ & $30 / 23 / 48$ & $40 / 29 / 31^{b}$ \\
\hline Body mass index $\left(\mathrm{kg} \cdot \mathrm{m}^{-2}\right)$ & $22.1 \pm 2.6$ & $22.8 \pm 2.9^{\mathrm{a}}$ \\
\hline C-peptide positive (\% patients) ${ }^{\mathrm{C}}$ & 32 & $59^{\mathrm{b}}$ \\
\hline $\mathrm{HbA}_{1}(\%)$ & $10.7 \pm 2.5$ & $9.9 \pm 2.1^{\mathrm{a}}$ \\
\hline $\begin{array}{l}\text { Patients with history of severe } \\
\text { hypoglycaemia }(\%)^{c}\end{array}$ & 26 & 27 \\
\hline Daily insulin dosage (IU/kg body weight) & $0.68 \pm 0.29$ & $0.65 \pm 0.28$ \\
\hline Insulin injections per day & $2.0 \pm 0.8$ & $2.0 \pm 0.8$ \\
\hline $\begin{array}{l}\text { Diabetes-related knowledge scores } \\
\text { (out of a maximum of } 39 \text { ) }\end{array}$ & $19 \pm 6$ & $18 \pm 6$ \\
\hline $\begin{array}{l}\text { Patients practising blood glucose self- } \\
\text { monitoring }(\%)^{c}\end{array}$ & 39 & 46 \\
\hline Current smokers (\%) & 48 & 43 \\
\hline $\begin{array}{l}\text { Retinopathy (\% patients) } \\
\text { none/non-proliferative/advanced }\end{array}$ & $70 / 29 / 2$ & $84 / 15 / 1^{b}$ \\
\hline $\begin{array}{l}\text { Proteinuria (\% patients) } \\
\leq 50 / 51-499 / \geq 500 \mathrm{mg} / 1\end{array}$ & $66 / 27 / 7$ & $81 / 15 / 4^{\mathrm{a}}$ \\
\hline
\end{tabular}

Values are means \pm SD or as indicated; differences significant at ${ }^{a} p<0.01,{ }^{b} p<0.001$; ${ }^{c}$ patients with newly-diagnosed diabetes excluded preparatory phase of the study, this method was introduced in all participating centres including the reference centre. Thus, the baseline $\mathrm{HbA}_{1}$ levels were measured by the same method in each hospital. At the follow-up examinations venous blood samples were taken from each patient and transported on ice to the laboratory of the reference centre where all laboratory measurements were performed. At the 3-year follow-up examination, $\mathrm{HbA}$ tc levels were measured additionally using the Diamat HPLC-analyser (normal range $4.5-5.5 \%$ ). Random C-peptide levels were measured using a human C-peptide assay (Behring, Marburg, FRG) and a value less than $0.1 \mathrm{nmol} / 1$ was considered negative.

\section{Statistical analysis}

Comparisons were made between the patients of the reference centre and the total patient group recruited from the general hospitals. Since some hospitals contributed a rather small number of patients comparisons between the reference centre and individual general hospitals were not made. Data are expressed as means \pm SD unless indicated otherwise. Patient characteristics at entry were compared by parametric and non-parametric tests for unpaired data (Student's $t$-test, one-way analysis of variance, Mann Whitney U-test). For quantitative outcome measures, groups were compared by the $t$-test and the Wilcoxon rank sum test. To assess changes over time within the groups, the paired samples $t$-test, analyses of variance for repeated measurements, the Wilcoxon matched-pairs signed-ranks test and the Friedman two-way analysis of variance were applied. The McNemar test and the chi-square test, respectively, were used for variables involving categorial classifications. Statistical significance was assumed at a two-tailed $p$ of less than 0.05 .

\section{Results}

\section{Patient characteristics and follow-up}

Table 1 summarizes the numbers of patients recruited, and those who were available and examined, respectively, at the three follow-up examinations, in each participating centre. Patients were either examined at their respective hospitals or visited at their homes (e.g. $43 \%$ home visits at the 3-year follow-up examination). Five patients had died during follow-up. Reasons for death were suicide (2), 
Table 3. Insulin therapy

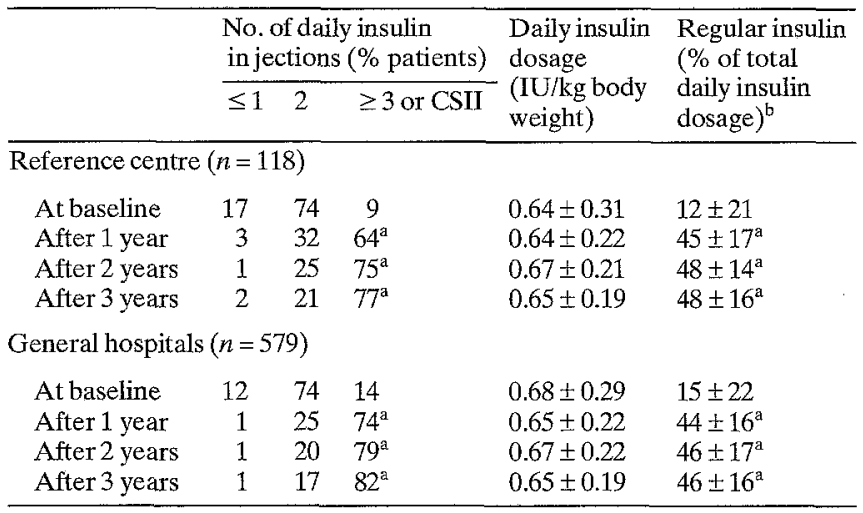

Compared to baseline values significantly different at a $p<0.0001$;

${ }^{b}$ for patients using continuous subcutaneous insulin infusion (CSII) prandial insulin dosages were used

Table 4. $\mathrm{HbA}_{1}\left(\mathrm{HbA}_{1 \mathrm{c}}\right)$ levels at baseline and at the follow-up examinations

\begin{tabular}{llllc}
\hline & Baseline & 1 year & 2 year & 3 year \\
\hline $\begin{array}{l}\text { Reference centre } \\
(n=118)\end{array}$ & $10.6 \pm 2.5$ & $9.3 \pm 2.0$ & $9.2 \pm 1.9$ & $\begin{array}{c}9.4 \pm 1.8 \\
(7.8 \pm 1.6)\end{array}$ \\
$\begin{array}{l}\text { General hospitals } \\
(n=579)\end{array}$ & $9.9 \pm 2.1$ & $9.0 \pm 1.9$ & $9.1 \pm 1.8$ & $\begin{array}{c}9.3 \pm 1.8 \\
(7.7 \pm 1.7)\end{array}$ \\
\hline
\end{tabular}

Values are means \pm SD. All follow-up values were significantly lower than respective baseline values $(p<0.0001)$

motor-cycle accident (1), cancer (1), and malpractice during an event of hypoglycaemia (1). After recruitment, during the 3-year follow-up period, a total of 42 patients changed place of residence to a distance greater than $100 \mathrm{~km}$ from their diabetes centres. No attempt was made to re-examine these persons, but they were contacted to verify that they were alive. These patients did not differ with respect to relevant clinical parameters from the patients who completed the study. A total of 51 patients declined to participate in one or more follow-up examinations (21 patients at 1 year, 40 at 2 years, and 40 at 3 years). These patients had higher initial $\mathrm{HbA}_{1}$ levels than those who participated in all examinations $(11.2 \pm 2.3 \%$ vs. $9.9 \pm 2.2 \%, p=0.001)$, whereas other clinical characteristics were comparable.

Table 2 shows selected baseline characteristics of the patients recruited from the reference centre and the group of patients recruited from the nine general hospitals. Patients from the reference centre had a higher level of formal education, a lower body mass index, and more of them had newly-diagnosed diabetes. On the other hand, they had more severe diabetes as indicated by higher initial $\mathrm{HbA}_{1}$ levels, a higher proportion of $\mathrm{C}$-peptide negative patients, and more patients with retinopathy and increased proteinuria concentrations. In the following, results are presented for the 697 patients who completed the 3-year study.

Diabetes-related knowledge scores were comparable between the reference centre and the general hospitals at baseline (Table 2), but were higher in the reference group immediately after participation in the TTP (33 vs 29 , $p<0.001$ ), and after 1 year ( 27 vs $26, p<0.05$ ). In both groups, during the 3 years of follow-up a cumulative $45 \%$ of patients reported to have consulted a physician specialized in diabetes at least once (reference centre: $31 \%$ during first year, $27 \%$ second year, $30 \%$ third year; general hospitals: $33 \%, 25 \%$, and $23 \%$, respectively).

\section{Insulin treatment and metabolic self-monitoring}

Initially, during the TTP, no patient was treated with CSII. At all three follow-up examinations more patients from the general hospitals than from the reference centre used CSII ( $8 \%$ vs $2 \%, p<0.01,10 \%$ vs $3 \%, p<0.05$, and $11 \%$ vs $5 \%, p<0.05$, respectively). The number of daily insulin injections increased significantly after the TTP $(p<0.0001$; Table 3$)$. The mean daily insulin dosage (IU/kg body weight) remained unchanged in the total patient groups (Table 3), but decreased in patients with a baseline diabetes duration of more than 1 year (reference group, $n=84$ : from $0.74 \pm 0.25$ at baseline, to $0.71 \pm 0.19$, $0.71 \pm 0.19$, and $0.69 \pm 0.18 \mathrm{IU} / \mathrm{kg}$ body weight, respectively, at the three follow-up examinations, $p<0.05$; general hospitals, $n=463$ : from $0.7 \pm 0.25$ to $0.68 \pm 0.22$, $0.68 \pm 0.21$, and $0.66 \pm 0.2$, respectively, $p<0.01$ ). At entry into the study, $30 \%$ and $39 \%$ of the patients, respectively, and at the 3-year follow-up $99 \%$ and $97 \%$, respectively, $(p<0.0001)$ used regular insulin preparations. In both groups, the relation between regular (prandial) insulin and intermediate acting (basal) insulin increased $(p<0.0001$, Table 3$)$.

At the 1-year follow-up $65 \%$, at 2 years $57 \%$, and at 3 years $51 \%$, respectively, of the patients presented a diabetes $\log$ book. The proportion of patients reporting blood glucose measurements more than twice daily increased in the reference centre from $12 \%$, at baseline, to $64 \%, 65 \%$ and $71 \%$, respectively, at the follow-up examinations $(p<0.0001)$, and in the general hospitals from $9 \%$ to $68 \%, 69 \%$ and $74 \%$, respectively, $(p<0.0001)$. The percentages of patients reporting daily glucose monitoring of urine decreased significantly (reference groups: from $14 \%$ at baseline, to $14 \%, 6 \%$ and $5 \%$ respectively $(p=0.03)$; general hospitals: from $15 \%$ to $12 \%, 5 \%$, and $3 \%$, respectively, $p<0.0001$ ).

\section{Metabolic control and acute complications}

Table 4 summarizes the results of $\mathrm{HbA}_{1}\left(\mathrm{HbA}_{1 \mathrm{c}}\right)$ levels. In the reference centre and the general hospitals $\mathrm{HbA}_{1}$ levels were significantly lower at all follow-up examinations when compared to baseline $(p<0.0001)$; the achieved degree of glycaemic control was comparable between the groups. Results did not significantly change after exclusion of the patients with newly-diagnosed diabetes from the analysis.

Severe hypoglycaemia: During the 3 years of the study in both patient groups a cumulative $22 \%$ of subjects had experienced one or more episodes of severe hypoglycaemia. $(16 \%$ and $12 \%$, respectively, one episode, and $6 \%$ and $10 \%$, respectively, two or more episodes). The cumulative number of episodes was 49 (incidence 0.14 cases per pa- 
Table 5. Frequency of severe hypoglycaemia in patients with a diabetes duration of more than 1 year at baseline

\begin{tabular}{lllll}
\hline & \multicolumn{3}{l}{$\begin{array}{l}\text { Percent patients with severe hypoglycaemia } \\
\text { (yearly incidence) }\end{array}$} \\
\cline { 2 - 5 } $\begin{array}{l}\text { Year before } \\
\text { intervention }\end{array}$ & \begin{tabular}{l} 
Follow-up \\
\cline { 3 - 5 }
\end{tabular} & 13 year & 2 year & 3 year \\
\hline $\begin{array}{l}\text { Reference centre } \\
(n=84)\end{array}$ & $10(0.18)$ & $11(0.16)$ & $14(0.19)$ \\
$\begin{array}{l}\text { General hospitals } \\
(n=463)\end{array}$ & $15(0.29)$ & $12(0.20)$ & $12(0.20)^{\mathrm{a}}$ & $9(0.12)^{\mathrm{b}}$ \\
\hline${ }^{\mathrm{a}} p<0.05,{ }^{\mathrm{b}} p<0.005$ compared to the year before intervention
\end{tabular}

Table 6. Hospitalisations during respective 3 -year periods prior to and after participation of the patients in the treatment and teaching programme (TTP)

\begin{tabular}{lcc}
\hline & $\begin{array}{l}3 \text { years } \\
\text { before TTP }\end{array}$ & $\begin{array}{l}3 \text { years } \\
\text { after TTP }\end{array}$ \\
\hline $\begin{array}{l}\text { Reference centre }(n=74)^{\mathrm{a}} \\
\text { Hospital admissions }\end{array}$ & \\
(cumulative, \% patients) & 31 & 44 \\
none & 40 & 31 \\
one & 29 & 25 \\
two or more & 11 & $5^{\mathrm{c}}$ \\
Hospital days (per patient per year) & & \\
General hospitals $(n=393)^{\mathrm{a}}$ & & \\
Hospital admissions & & \\
(cumulative, \% patients) & & \\
none & 33 & $45^{\mathrm{b}}$ \\
one & 35 & $30^{\mathrm{b}}$ \\
two or more & 32 & $25^{\mathrm{b}}$ \\
Hospital days (per patient per year) & 7 & $4^{\mathrm{d}}$
\end{tabular}

${ }^{a}$ Only patients with a baseline diabetes duration of more than 3 years were included. Significant differences compared to pre-study values

${ }^{\mathrm{b}} p<0.05,{ }^{\mathrm{c}} p<0.0005,{ }^{\mathrm{d}} p<0.0001$

tient per year) and 279 (incidence 0.16), respectively. Table 5 shows the yearly incidence rates of severe hypoglycaemia for patients with a diabetes duration of more than one year at entry into the study during the year before and the 3 years after participation of the patients in the TTP. In the general hospitals incidence rates were significantly lower during the second and third year of follow-up compared to the year before intervention. No significant change was observed in the reference centre. The proportion of severe hypoglycaemic events treated with glucagon by relatives or significant others increased $(p<0.001)$ [reference centre: from $5 \%$ (year before intervention), to $21 \%$ (first year), $50 \%$ (second year), and $44 \%$ (third year); general hospitals: from $14 \%$ to $30 \%$, $37 \%$, and $52 \%$, respectively], whereas those resulting in hospitalisation decreased $(p<0.01)$ (reference centre: from $90 \%$ to $29 \%, 31 \%$, and $44 \%$; general hospitals: from $45 \%$ to $35 \%, 36 \%$, and $33 \%$, respectively). The remaining events of severe hypoglycaemia were treated by physicians without resulting in hospitalisation.

Ketoacidosis was a rare event in both patient groups (one event in the reference group and 11 in the general hospitals group during the 3 years of follow-up).
Body mass index changed to a similar extent in the reference group (from $22.0 \pm 2.5$ to $22.8 \pm 2.6$ after 3 years, $p<0.0001$ ) and the general hospitals group (from $22.9 \pm 2.9$ to $23.7 \pm 2.9, p<0.0001$ ).

Hospitalisations: During the 3 years of follow-up, a cumulative $48 \%$ of patients from the reference centre and $47 \%$ from the general hospitals, respectively, had no hospital admission, $32 \%$ and $30 \%$, respectively, had one, and $30 \%$ and $23 \%$, respectively, had two or more hospital admissions. In both groups, hospitalisations and days spent in hospital were significantly lower during the 3 years after participation of the patients in the TTP when compared to the 3 years before the study $(p<0.0001$, Table 6$)$.

Subgroup of patients with CSII: At the 3-year follow-up examination 68 patients used CSII. Compared to the patients using injection therapy $(n=629)$ there were more females among CSII patients ( $66 \%$ vs $55 \%, p<0.01$ ), and they had a longer diabetes duration $(11 \pm 8$ years vs $8 \pm 7$ years, $p<0.02$ ). CSII patients had higher diabetesrelated knowledge scores, both before $(21 \pm 6$ vs $18 \pm 6$, $p<0.0001$ ), immediately after the TTP ( $30 \pm 4$ vs $29 \pm 5$, $p<0.02)$, and at the 1-year follow-up ( $29 \pm 4$ vs $26 \pm 5$, $p<0.001$ ); more patients reported measuring blood glucose more than twice daily ( $94 \%$ vs $71 \%, p<0.0001$ ), and they used less insulin at 3 years $(0.57 \pm 0.15$ vs $0.65 \pm 0.21 \mathrm{IU} / \mathrm{kg}$ body weight, $p<0.0001$ ), though insulin dosages were not significantly different at entry into the study $(0.62 \pm 0.18$ vs $0.65 \pm 0.28)$. CSII patients had comparable $\mathrm{HbA}_{1}$ levels at entry into the study $(9.7 \pm 2.3 \mathrm{vs}$ $10.0 \pm 2.2 \%)$ and after 3 years $(9.0 \pm 1.7$ vs $9.3 \pm 1.8 \%)$, but they had a higher incidence of severe hypoglycaemia ( 0.22 vs 0.11 cases per patient during the third year, $p<0.05$ ), although the incidence rates were not significantly different during the year before the study $(0.19 \mathrm{vs}$ $0.29)$. The incidence of ketoacidosis was higher during CSII treatment $(0.03$ vs 0.003 cases per patient during the third year, $p<0.005)$. In addition, hospitalisation rates were higher during CSII therapy (a cumulative $96 \%$ vs $48 \%$ of patients with hospital admissions during the 3 years of follow-up, $p<0.0001$; and 8 vs 4 hospital days per patient per year, $p<0.001$ ).

\section{Discussion}

The present study shows that intensified insulin treatment based upon a structured 5-day in-patient training programme can be effectively and safely provided in general hospitals. For up to 3 years, main outcome measures of diabetes care were comparable between the diabetes centre of the University hospital of Düsseldorf and nine general hospitals.

The effectiveness of the educational and treatment approach used in this study has been documented previously in several uncontrolled studies $[2,5,7,9]$ and in a prospective randomized controlled investigation [8]. Thus, the aim of the present study was not to demonstrate the effectiveness of a particular teaching programme or treatment regimen, but to prove the feasibility of translating modern 
insulin treatment to general medicine departments without increasing the risk of severe hypoglycaemia.

Not unexpectedly, patients recruited in the University hospital differed in some characteristics from those of the general hospitals. A higher educational level among patients from the reference centre may be due to a certain degree of patient self selection, i.e. patients with a higher degree of education may opt more readily for participation in an intensified insulin treatment and teaching programme at a specialised diabetes centre than patients with lower education. On the other hand, patients admitted to the University hospital had their diabetes less well controlled and more of them had diabetic late complications reflecting a referral policy which is in accordance with the particular scope of a specialized diabetes centre.

Despite these differences between the patients of the reference centre and the general hospitals main outcome measures were comparable. Insulin therapy was intensified to a similar extent. In both groups about $80 \%$ of patients injected insulin at least three times daily or used CSII treatment, and about $70 \%$ reported blood glucose self-monitoring more than twice daily. In addition, intensified insulin therapy was carried out safely in both groups. Yearly incidence rates of severe hypoglycaemia either remained unchanged (reference centre) or even decreased (general hospitals) during the years following participation of the patients in the TTP. This result is in contrast to the findings of the Diabetes Control and Complications Trial (DCCT) and other research studies, where intensification of insulin therapy has substantially increased the risk of severe hypoglycaemia $[3,4,12]$. It is of note, that in the present study patients who had a particularly high risk of subsequent severe hypoglycaemia, e.g. those with a history of repeated severe hypoglycaemia [3,8,12], were not excluded from the protocol, whereas the DCCT full-scale trial has made such patients ineligible [13]. The results of the present study are in support of our previous observations, that intensification of insulin therapy based upon a structured training programme does not lead to an increased risk of severe hypoglycaemia. It is of note, that the TTP evaluated in the present study was based upon the use of multiple daily insulin injections. Thus, patients already being treated with CSII on admission were not included in the study, although later change to CSII was not an exclusion criteria. We have previously reported that CSII treatment can be effective and safe if performed according to specific recommendations as outlined by Chantelau et al. [10]. However, under the conditions of the present study, the outcome of CSII was less favourable than multiple insulin injection therapy.

Finally, the programme was comparably effective in lowering $\mathrm{HbA}_{1}$ values in both the specialized centre and the general hospitals. The achieved degree of metabolic control was comparable to previous evaluation studies of the programme. In addition, the mean $\mathrm{HbA}_{1 \mathrm{c}}$ level of $7.7 \%$ at the 3 -year follow-up is comparable to the value reported from the DCCT experimental group after a similar study period [13]. It is notable however, that in the present study $\mathrm{HbA}_{1}$ values were fair even on admission of the patients to the study. Nevertheless, the observed decrease of $\mathrm{HbA}_{1}$ levels by about $1 \%$ appears to be of clini- cal relevance $[14,15]$. An explanation for the comparably low initial $\mathrm{HbA}_{1}$ levels may be the high proportion of participating patients with a short duration of diabetes, e.g. $20 \%$ had a diabetes duration of one year or less. This observation reflects a referral policy which is entirely in accordance with the objectives of the intervention programme. Patients should participate in the TTP as soon as possible after manifestation of the disease.

The TTP was associated with an impressive subsequent decrease in hospitalisations, an observation which cannot be explained by concomitant changes in hospitalisation patterns of the general population [9]. The effects were similar for patients of the diabetes centre and the general hospitals, underscoring the overall quality of the programmes provided in the general medicine departments.

It could possibly be argued that the reductions of both the $\mathrm{HbA}_{1}$ values and the frequency of severe hypoglycaemia seen in this study might simply be due to a socalled study effect or due to an overall improvement of diabetes care in Germany during the study period. Although counselling of the patients at the yearly follow-up examinations was not part of the protocol, a study effect might have occurred. However, in previous controlled intervention trials in Type 1 diabetic patients it has emerged that so-called study effects on metabolic control, if they occur at all, are short lived. Usually, they do not last beyond 6 months $[8,13,16,17]$. Thus, in one study addressing this aspect [16], intensive individual counselling by a diabetologist during 12 patient visits led only to a transient fall of $\mathrm{HbA}_{1}$ levels. After 6 months, at the twelfth visit, $\mathrm{HbA}_{1}$ values were as high as at the first visit. Even the additional introduction of blood glucose self monitoring led only to a short-lived improvement of metabolic control. At the end of the study, after a total of 15 months, $\mathrm{HbA}_{1}$ levels were on average $1 \%$ higher than before the intervention. In the DCCT [13], in the control group $\mathrm{HbA}_{1 \mathrm{c}}$ levels after 3 years were marginally higher than the initial values despite physician contact every 3 months. Finally, in a randomized controlled multicentre evaluation study of an education programme in the Netherlands for Type 1 diabetic patients of four weekly 3 -h group sessions, $\mathrm{HbA}_{1 \mathrm{c}}$ levels remained unchanged at about $9 \%$ both in the control group and in the intervention group [17]. Only limited information exists on the overall quality of Type 1 diabetes care in Germany. However, data recently collected in a German multicentre study [18] from a sample of more than 500 Type 1 diabetic patients, showed that the incidence of severe hypoglycaemia was disturbingly high, i.e. 0.45 cases per patient per year at an average $\mathrm{HbA}_{1}$ value comparable to that at recruitment into the present study. In another study from Germany [19] evaluating about 200 Type 1 diabetic patients who were treated with CSII at one specialized diabetes centre the incidence of diabetic ketoacidosis was 0.19 cases per patient per year, and of severe hypoglycaemia treated by a physician, 0.25 . Thus, unfortunately, there is no reason to assume that diabetes care in general has improved for the majority of the German Type 1 diabetic patients during recent years.

Several prerequisites appear indispensable for the successful translation of intensified insulin TTPs to general medicine departments. Firstly, the availability of trained 
diabetes educators to carry out the programme are mandatory. Therefore, the implementation of an official postgraduate training course for diabetes educators by the German Diabetes Association [11] has provided the basis for a nationwide distribution of structured insulin treatment and teaching programmes. Secondly, the education of the patients has to follow a curriculum, and treatment regimens have to take into account patients' desires to participate in treatment decision making. The prospect of liberal diet and increasing flexibility of other aspects of daily life, are considered major determinants in motivating patients to practise intensified insulin therapy on a long-term basis. Consequently, intensification of insulin treatment and training of the patients in day-to-day self adaptation of insulin dosages are indispensable objectives of this programme. It is in support of these considerations, that in the present study patients adhering to the objectives of the TTP of blood glucose monitoring at least three times per day had better $\mathrm{HbA}_{1}$ levels than patients who did not follow these recommendations ( $9 \%$ vs $10 \%$ after 3 years). Intervention programmes that have disregarded these aspects of treating and teaching Type 1 diabetic patients were unsuccessful in improving glycaemic control [17].

In conclusion, the present study has demonstrated that intensified insulin therapy can be performed effectively and safely in general hospitals. The prerequisite for success is a structured TTP performed by specially trained diabetes educators. Translating such programmes from specialized diabetes centres to general hospitals can make effective insulin therapy amenable to all Type 1 diabetic patients.

Acknowledgements. The following general hospitals have participated in the study: Katholisches Krankenhaus St. Josef (Dr. med. F.Best), Essen; Elisabeth Krankenhaus (Prof. Dr. med. J. Bertrams, Dr. med. H.-J. Krönke, Dr. med. B. Schulze-Schleppinghoff), Essen; Kreiskrankenhaus (Dr. med. B. Lippmann-Grob), Offenburg; Städtisches Krankenhaus (Dr. med. J. Merkt, Dr. med. J. Weimer), Heilbronn; Krankenhaus KöIn-Porz (Dr. med. G. Willms), Köln; St. Vinzenz Hospital (Dr. med. B. Gymnich, Dr. med. J.Kersken), Dinslaken; Evangelisches Krankenhaus Kredenbach (Dr. med. G.Schmiđt, Dr. med. L. Brügmann), Kreuztal-Kredenbach; Krankenanstalten Gilead (Dr. med. H.-H.Echterhoff), Bielefeld; Krankenhaus Düren (Prof. Dr. med. H.Leonhardt, Dr. med.F. Striesow), Düren. In addition, we thank all the nurses and dietitians for their dedicated co-operation throughout the study. This study was financed through a grant by the Bundesminister für Forschung und Technologie (Qualitätskontrolle und -sicherung der Langzeittherapie des Typ 1 Diabetes mellitus, Förderkennzeichen: 0706322).

\section{References}

1. Chantelau EA, Gösseringer $G$, Sonnenberg GE, Berger $M$ (1985) Moderate intake of sucrose does not impair metabolic control in pump-treated diabetic out-patients. Diabetologia 28: 204-207

2. Chantelau EA, Frenzen A, Gösseringer G, Hansen I, Berger M (1987) Intensive insulin therapy justifies simplification of the diabetes diet: a prospective study in insulin-dependent diabetics. Am J Clin Nutr 45: 958-962
3. The DCCT Research Group (1987) Diabetes control and complications trial (DCCT): results of feasibility study. Diabetes Care 10:1-19

4. The Kroc Collaborative Study Group (1984) Blood glucose control and the evolution of diabetic retinopathy and albuminuria. $\mathrm{N}$ Engl J Med 311:365-372

5. Mühlhauser I, Jörgens V, Berger M et al. (1983) Bicentric evaluation of a teaching and treatment programme for type 1 (insulindependent) diabetic patients: improvement of metabolic control and other measures of diabetes care for up to 22 months. Diabetologia 25: $470-476$

6. Assal JP, Mühlhauser I, Pernet A, Gfeller R, Jörgens V, Berger M (1985) Patient education as the basis for diabetes care in clinical practice and research. Diabetologia 28: 602-613

7. Mühlhauser I, Berger M, Sonnenberg GE et al. (1985) Incidence and management of severe hypoglycaemia in 434 adults with insulin-dependent diabetes mellitus. Diabetes Care 8: 268-273

8. Mühlhauser I, Bruckner I, Berger M et al. (1987) Evaluation of an intensified insulin treatment and teaching programme as routine management of type 1 (insulin-dependent) diabetes. The Bucharest-Düsseldorf Study. Diabetologia 30: 681-690

9. Mühlhauser I, Klemm AB, Boor B, Scholz V, Berger M (1986) Krankenhausaufenthalts- und Arbeitsunfähigkeitszeiten bei Patienten mit Type 1 Diabetes. Einfluß eines Diabetes-Behandlungs- und Schulungsprogramms. Dtsch Med Wochenschr 111: $854-857$

10. Chantelau E, Spraul M, Mühlhauser I, Gause R, Berger M (1989) Long-term safety, efficacy and side-effects of continuous subcutaneous insulin infusion treatment for type 1 (insulin-dependent) diabetes mellitus: a one centre experience. Diabetologia 32: $421-426$

11. Scholz V (1984) Course for diabetes educators. Diabetes Educator 10 (Special): $80-84$

12. The DCCT Research Group (1991) Epidemiology of severe hypoglycaemia in the diabetes control and complications trial. Am J Med 90: 450-459

13. The DCCT Research Group (1990) Update. Diabetes Care 13: $427-433$

14. Brinchmann-Hansen O, Dahl-Jorgensen K, Sandvik L, Hanssen KF (1992) Blood glucose concentrations and progression of diabetic retinopathy: the seven year results of the Oslo study. $\mathrm{Br}$ Med J 304: 19-22

15. Feldt-Rasmussen B, Mathiesen ER, Jensen $T$, Lauritzen $T$, Deckert T (1991) Effect of improved metabolic control on loss of kidney function in type 1 (insulin-dependent) diabetic patients: an update of the Steno studies. Diabetologia 34: 164-170

16. Worth R, Home PD, Johnston DG et al. (1982) Intensive attention improves glycaemic control in insulin-dependent diabetes without further advantage from home blood glucose monitoring: results of a controlled trial. Br Med J 285: 1233-1240

17. de Weerdt I, Visser AP, Kok GJ, de Weerdt O, van der Veen EA (1991) Randomized controlled multicentre evaluation of an education programme for insulin-treated diabetic patients: effects on metabolic control, quality of life, and costs of therapy. Diabetic Med 8: 338-345

18. Mühlhauser I, Heinemann L, Fritsche E, von Lennep K, Berger M (1991) Hypoglycemic symptoms and frequency of severe hypoglycemia in patients treated with human and animal insulin preparations. Diabetes Care 14: 745-749

19. Braun D, Unger H, Henrichs HR (1991) Insulinpumpentherapie bei Diabetes mellitus. Akt Endokr Stoffw 12: 195-202

Received: 20 July 1992 and in revised form: 18 September 1992

Dr. I. Mühlhauser

Medizinische Klinik der Universität Düsseldorf

Abteilung Stoffwechsel und Ernährung

Moorenstrasse 5

W-4000 Düsseldorf, FRG 